\title{
Psychiatric nurses' attitudes towards children visiting their parents in psychiatric inpatient units - Corrigendum
}

\author{
D. Houlihan, D. Sharek and A. Higgins
}

First published online 31 October 2013

doi: http:/ /dx.doi.org/10.1017/ipm.2013.50, Published by Cambridge University Press 2013

The authors would like to correct two mistakes in the Handley reference:

Handley C, Farrell GA, Josephs A, Hanke A, Hazeldon M (2001). The Tasmanian children's project: the needs of children with a parent/carer with a mental illness. Austrailian and New Zealand Journal of Mental Health Nursing 10, 221-228.

Should be:

Handley C, Farrell GA, Josephs A, Hanke A, Hazelton M (2001). The Tasmanian children's project: the needs of children with a parent/carer with a mental illness. Australian and New Zealand Journal of Mental Health Nursing $10,221-228$.

\section{Reference}

Houlihan D, Sharek D, Higgins A. (2013). Psychiatric nurses' attitudes towards children visiting their parents in psychiatric inpatient units. Irish Journal of Psychological Medicine, available on CJO2013. doi:10.1017/ipm.2013.50. 